\title{
Development of a screening instrument for risk factors of persistent pain after breast cancer surgery
}

\author{
R Sipilä', A-M Estlander', T Tasmuth ${ }^{2}$, M Kataja ${ }^{3}$ and E Kalso*, I \\ 'Department of Anaesthesia and Intensive Care, Pain Clinic, Helsinki University Central Hospital, PO Box 140, 00029 HUS, Helsinki, Finland; \\ ${ }^{2}$ Department of Oncology, Helsinki University Central Hospital, PO Box 180, 00029 HUS, Helsinki, Finland; ${ }^{3}$ National Institute for Health and Welfare, \\ Pirttikatu 6 D, FIN-33560 TAMPERE, Helsinki, Finland
}

\begin{abstract}
BACKGROUND: Persistent postsurgical pain can have a significant effect on the quality of life of women being treated for breast cancer. The aim of this prospective study was to develop a screening tool to identify presurgical demographic, psychological and treatmentrelated factors that predict persistence of significant pain in the operated area after 6 months from surgery.

METHODS: Background and self-reported questionnaire data were collected the day before surgery and combined with treatmentrelated data. Pain in the operated area was assessed 6 months after surgery with a questionnaire. The Bayesian model was used for the development of a screening tool.

RESULTS: Report of preoperative chronic pain, more than four or more previous operations, preoperative pain in the area to be operated, high body mass index, previous smoking and older age were included in the six-factor model that best predicted significant pain at the follow-up in the 489 women studied.

CONCLUSION: A six-factor risk index was developed to estimate the risk of developing significant pain after breast cancer surgery. Neither treatment- nor mood-related variables were included in the model. Identification of risk factors may lead to prevention of persistent postsurgery pain. This tool could be used for target prevention to those who are at the highest risk of developing persistent postsurgery pain.

British Journal of Cancer (2012) 107, |459-|466. doi:I0.1038/bjc.2012.445 www.bjcancer.com
\end{abstract}

(c) 2012 Cancer Research UK

Keywords: breast cancer; persistent pain; breast surgery; risk factors; anxiety; screening tool

Most of the women who are diagnosed with breast cancer undergo surgery and receive adjuvant therapies. Owing to early diagnosis and effective treatments approximately 9 out of 10 women are still alive after 5 years from the diagnosis. With improved survival rates the research is increasingly focused on the quality of life of breast cancer survivors. One of the most studied complications of breast cancer treatment is persistent pain following breast cancer surgery (Stevens et al, 1995; Poleshuck et al, 2006).

Macrae (2001) has defined chronic postsurgical pain as pain that develops after surgery and persists for at least 2 months. Prevalence of chronic pain following breast cancer surgery varies from 10 to $50 \%$ depending on study design and type of surgery (Kehlet et al, 2006). Several studies show that the prevalence can be as high as $50 \%$ (Poleshuck et al, 2006; Gärtner et al, 2009; Andersen and Kehlet, 2011).

Chronic pain can dramatically affect the patients' quality of life and psychological well-being (Vlaeyen and Linton, 2000; Caffo et al, 2003). Anxiety, depression and other psychological factors are known to be the risk factors for prolonged pain after surgery (Hinrichs-Rocker et al, 2009; Löbner et al, 2012). The risk factor of preoperative psychological distress for persistent pain after breast cancer surgery has been studied, but the evidence is inconsistent (Tasmuth et al, 1996a; Poleshuck et al, 2006; Kudel et al, 2007).

*Correspondence: Dr E Kalso; E-mail: eija.kalso@helsinki.fi Received I5 May 2012; revised 10 August 2012; accepted 31 August 2012
Other risk factors suggested in previous studies have included young age, preoperative pain in the breast, the intensity of acute postoperative pain, pain in locations not related to breast cancer, obesity, type of surgery and adjuvant therapy (Tasmuth et al, 1997; Jung et al, 2005; Poleshuck et al, 2006; Kudel et al, 2007; Fecho et al, 2009; Gärtner et al, 2009).

As Andersen and Kehlet (2011) noticed in the first review on risk factors for persistent pain after breast cancer surgery, the heterogeneity of the studies makes the comparison difficult. Different presurgical and postsurgical assessment methods have been used, the length of the follow-up period has varied (Katz et al, 1996; Poleshuck et al, 2006), and many of the studies have not evaluated psychological risk factors (Vilholm et al, 2008; Gärtner et al, 2009). Most of the studies are retrospective. The results regarding risk factors and incidence of persistent pain are also inconsistent between prospective and retrospective studies (Andersen and Kehlet, 2011).

In this prospective study we assessed possible risk factors for the development of persistent pain after breast cancer surgery in a large population of women. We also used a large range of questionnaires to identify risk factors for pain chronification after breast cancer surgery. The ultimate goal was to create a screening tool to identify factors that predict significant persistent pain in the operated area at the 6 months' follow-up. Identification of risk factors may lead to prevention of persistent postsurgery pain. Ideally, this tool could be used to target possible preventive measures to those patients who are at the highest risk. 


\section{MATERIALS AND METHODS}

\section{Patients}

The study was open to women aged 18-75 years old with histologically proven newly diagnosed invasive breast cancer (T1-4 N0-3 M0) and who were to undergo either modified radical mastectomy or breast conserving surgery with sentinel node biopsy or axillary clearance. Axillary nodes of levels I and II were removed. If suspicion of level II metastases arose during surgery, also level III nodes were removed.

The local clinical guidelines for treatment of early breast cancer were based on international guidelines (Goldhirsch et al, 2005, 2007). Adjuvant treatment consisted of radiotherapy, chemotherapy and endocrine therapy. Most patients (>80\%) received docetaxel in addition to 5-fluorouracil, epirubisine and cyclophosphamide.

Patients were recruited from the Unit for Breast Surgery at the Women's Hospital, Helsinki University Central Hospital. The study group was comprised of all consenting consecutive patients who were operated on between 3 August 2006 and 13 August 2009. Oral and written consent was obtained from all patients. The Coordinating Ethics Committee of the Helsinki University Central Hospital approved the study protocol (136/E0/2006).

\section{Questionnaires and treatment-related data}

The patients filled in the questionnaires the day before surgery. Background data included age, weight and height (calculated to body mass index (BMI); for the statistical analyses divided into three groups: $\mathrm{BMI} \leqslant 25,26-30$ and $\geqslant 31$ ), number of previous operations (other than breast surgery), previous chronic pain of any kind (e.g. fibromyalgia, low back pain, headaches; no/yes), preoperative use of hormonal replacement therapy (no/yes), use of alcohol (no/under 6 doses per week/over 6 doses per week) and smoking (never/yes/stopped).

Pain in the area of the breast to be operated was assessed before surgery by a numerical rating scale (NRS 0-10; questionnaire data). The patients were asked to assess the average pain intensity during the previous week in four separate regions: the breast, the axilla, the upper arm and the lower arm. The highest rating in any one of these locations was used as an indication of pain intensity (worst pain).

Before surgery, the patients also answered psychological questionnaires. Sum scores of the Beck depression inventory (BDI) (Beck et al, 1961) and the Spielberger Anxiety Questionnaire including State and Trait Anxiety scales were used (Spielberger et al, 1983).

The records of the patients were reviewed for the type of surgery (breast conserving surgery with sentinel node biopsy; breast conserving surgery with axillary evacuation, mastectomy with sentinel node biopsy, mastectomy with axillary evacuation), the stage and spread of the tumour, complications of surgery: wound infection or postoperative bleeding (no/yes), use of adjuvant endocrine therapy (no/yes), chemotherapy (no/yes) or radiotherapy (no/yes) and acute complications of radiotherapy (no or mild erythema/erythema with skin desquamation). All patients were given oral paracetamol during hospital stay. Intravenous oxycodone consumption using patient-controlled analgesia after surgery $\left(\mathrm{mg} \mathrm{kg}^{-1}\right.$ per $\left.20 \mathrm{~h}\right)$ was used as a proxy for postoperative pain. The patients were divided into three prognostic risk categories defined by the 10th St Gallen expert consensus meeting panel: low-, intermediate- and high-risk groups (Goldhirsch et al, 2007).

At 6 months from surgery a questionnaire was sent to the patients. Presence of pain and its intensity were assessed as before surgery. The patients were divided into two groups based on pain severity in the operated area at the 6 months' follow-up. The categories were worst pain NRS $\leqslant 3$ (no or mild pain) and worst pain $\geqslant 4$ (moderate to severe pain) (Gerbershagen et al, 2011; Johansen et al, 2012).

\section{Statistics}

Correlations between the outcome variable, pain in the operated area, and the background- and treatment-related data were calculated (Spearman rank-order correlations). Univariate analyses were performed using Student's $t$-test and $\chi^{2}$-tests. The Bayesian method (Pelkonen et al, 2012) was used as the multivariate method to create a model to predict pain at the 6 months' follow-up. The Bayesian procedure is the following: first, the variable that best explains the outcome is selected. In the following steps the programme searches through the data and selects, one by one, the variable that improves the model. The procedure stops when none of the remaining variables improves the result. The aim is to find an optimal subset of variables that best explain the outcomes.

In this study, the Bayesian analyses were performed in three stages. First, presurgery data (questionnaire data and sum scores from the psychological inventories) were analysed. Second, surgery- and adjuvant treatment-related data were analysed and finally, questionnaire and treatment data were combined and analysed. The sum variables were produced through logarithmic transformation of the Bayesian values (Kurki and Kataja, 1996). An easily applicable multifactorial risk index was finally constructed. A solution comprising of six factors was chosen.

\section{RESULTS}

A total of 685 patients were invited to participate and 85 patients declined. Of the 600 patients 45 were excluded ( 28 patients had metastases and 17 patients had noninvasive carcinoma, ductal carcinoma in situ or lobular carcinoma in situ) and two patients had missing data. Of the remaining 553 patients, 489 (88\%) answered and returned the 6 months' questionnaires. No statistically significant differences were found among the 489 included patients and the 64 dropouts in any of the variables. There was a small amount of coincidental missing data (1-3 patients) in some of the variables.

The mean age was 56.4 years (s.d. 9.28, range 30-75) and the mean BMI was 25.3 (s.d. 4.28, range 16-43). The mean of the Beck depression index sum score was 8.3 (s.d. 6.8, range 0-39), the mean STAI state anxiety was 40.4 (s.d. 11.55 , range $20-74$ ), whereas the mean STAI trait anxiety was 36.8 (s.d. 9.62, range 20-75). The main results of the categorical variables are: $24.1 \%$ of the patients reported chronic pain problems such as fibromyalgia, low back pain or headache; $52.6 \%$ had used hormone replacement therapy, $91.4 \%$ had had previous surgery and $10.7 \%$ had had four or more operations. The patients' reports regarding use of alcohol and smoking were: $14.1 \%$ did not use alcohol at all, $64.8 \%$ used $<6$ doses per week and $17.4 \%>6$ doses per week; $57.5 \%$ reported that they never had smoked, $18.6 \%$ smoked regularly or occasionally and $23.9 \%$ reported that they had stopped smoking.

Before surgery, 168 patients $(34.6 \%)$ reported no pain and 286 patients $(58.8 \%)$ mild pain (NRS $1-3)$, whereas 32 patients $(6.6 \%)$ reported moderate to severe pain (NRS $\geqslant 4$ ) in at least one of the locations (breast, axilla, upper arm, lower arm). Of these, nine patients had pain in two or more locations.

The majority of the patients, $92.4 \%$, had a BDI score indicating no or mild depression (score $0-18$ ), whereas $7.6 \%$ had a score of 19 or more (moderate or severe depression). The frequency distributions of the scores on the STAI anxiety scales were the following for state anxiety: $54.7 \%$ score $20-39$ (low), $38.4 \%$ score $40-59$ (moderate), 6.9\% score 60-80 (high) and for trait anxiety: $70.2 \%$ score 20-39 (low), 27.5\% score 40-59 (moderate), $2.3 \%$ score 
60-80 (high). Correlations between depression and anxiety sum scores were strong, ranging from 0.65 to 0.77 .

According to St Gallen's prognostic risk groups of breast cancer, $17.4 \%$ of the patients were in the low-risk group, $64.2 \%$ in the intermediate-risk group and $18.4 \%$ in the high-risk group. The patients had the following types of surgery: breast conserving surgery with sentinel node biopsy $41.7 \%$, breast conserving surgery with axillary evacuation $22.5 \%$, mastectomy with sentinel node biopsy $12.9 \%$ and mastectomy with axillary evacuation $22.9 \%$. The average need for oxycodone during the first $20 \mathrm{~h}$ following the operation was $10.6 \mathrm{mg} \mathrm{kg}^{-1}$ (s.d. 6.54, range 0-39). Approximately, one patient in five $(18.6 \%)$ had complications related to surgery. Of these 91 patients, $75.8 \%$ had a postoperative wound infection, $22 \%$ had wound bleeding and two patients had other complications. The majority of the patients received adjuvant chemotherapy $(60.5 \%)$ and postoperative radiotherapy (72.6\%). Thirty patients $(6.1 \%)$ had acute erythema with skin desquamation. Postoperative adjuvant endocrine therapy was given to $72 \%$ of the patients.

At 6 months after surgery, 152 patients $(31.1 \%)$ reported no pain and 274 patients $(56.0 \%)$ mild pain (NRS $1-3$ ), whereas 63 patients $(12.9 \%)$ reported moderate to severe pain $(\mathrm{NRS} \geqslant 4)$ in one or more locations (breast, axilla, lower arm or upper arm). Two patients had missing data and were not included in the analysis. Three patients reported pain in all four locations and they all reported high pain intensity (NRS 7-9). Of the 32 patients who reported moderate to severe pain preoperatively, 23 (72\%) reported no or mild pain at the follow-up, whereas 9 patients $(28 \%)$ still reported moderate to severe pain.

The majority of the correlations between the outcome variable, pain at the follow-up and background/treatment-related data were statistically significant $(P<0.01)$ although low, ranging between $r=0.12$ and $r=0.29$ (Table 1 ).

The Bayesian optimal prediction model is presented in Table 1. Report of preoperative chronic pain of any kind, high number of previous operations, preoperative pain in the area to be operated, high BMI $(>30)$, previous smoking and older age were related to more severe pain at the follow-up. The sensitivity of the optimal sixfactor model was $33 \%$ and the specificity $95 \%$. As the sensitivity of the optimal model was only $33 \%$ we further developed the best model for screening purposes. The efficiency for correct prediction was $88 \%$ and the total error rate was $12 \%$.

On the basis of this six-factor model, due to its ease of use in clinical practice, a simple sum score was created as an estimation of the risk of developing moderate or severe chronic pain in the operated area. The factors were weighted based on their relative contribution to the risk (Appendix Table A1). The total maximum score of this model is 100 . The higher the sum score, the higher is the risk for developing chronic pain. A cutoff level of 20 was chosen as the risk limit for screening purposes. The sum score of 20 identifies $81 \%$ of those who will develop persistent pain but there will be $56 \%$ false-positive assumptions (Appendix Table A2). As the sum score increases, the specificity increases, whereas the sensitivity decreases.

\section{DISCUSSION}

The goal of this prospective study was to identify possible risk factors for significant persistent pain in the operated area at 6 months following breast cancer surgery and to use these factors to create a risk factor assessment tool.

The results of the multivariate analyses indicate that the model including the following six factors predicted significant pain at the 6 months' follow-up: previous chronic pain of any kind, high number of previous operations, preoperative pain in the area to be operated, high BMI, previous smoking and older age. On the basis of this sixfactor model, a sum score, which is easy to use in clinical practice, was created as an estimation of the risk of developing moderate or severe persistent pain in the operated area. The risk estimation could be used to target possible preventive measures to those patients who are at the highest risk of developing moderate to severe persistent pain. To our knowledge, such an approach has not been used before. Also, most previous studies in this field have been retrospective. Andersen and Kehlet (2011) identified in their extensive review many inconsistencies among the results of prospective and retrospective studies. Consequently, we have chosen to discuss our results mainly in relation to the few previously published prospective studies, if available.

Previous chronic pain of any kind is known to be a potential risk factor for persistent pain after other types of surgery (Gerbershagen et al, 2009; Kainu et al, 2010). One retrospective study (Gärtner et al, 2009) has suggested that women with chronic pain are more likely to develop postsurgical pain after breast cancer surgery. Chronic pain is a common problem and often unnoticed in health care. The $25 \%$ incidence of chronic pain in the current study agrees with the previous results on the incidence of chronic pain in Finnish and European females in general (Breivik et al, 2009). Previous chronic pain can predispose to persistent postsurgery pain through multiple mechanisms, including shared genetic and psychosocial factors. It is also possible that chronic pain may sensitise the pain system facilitating the development of chronic pain after new injury.

To our knowledge the number of previous operations has not been considered as a risk factor in published prospective studies. In our study, a high number of previous operations was one of the variables predicting persistent pain. In theory, it would be possible that several operations have sensitised the central nervous system. It is also possible that the need for several operations is related to more chronic diseases and systemic inflammation causing more chronic pain and sensitisation of the pain system.

In other types of surgery, preoperative pain in the area to be operated has been found to be a possible risk factor for persistent pain (Kehlet et al, 2006). The relation of preoperative pain in the breast area to persistent pain is unclear (Andersen and Kehlet, 2011). It is possible that patients with a breast cancer diagnosis pay more attention to different sensations in the area where the tumour has been diagnosed. This heightened awareness may increase the sensation of pain (Eccleston and Crombez, 1999). Preoperative pain can also be related to regional inflammation caused by the tumour (Cabodi and Taverna, 2010). Unlike our study, Poleshuck et al (2006) did not find any connection between preoperative breast pain and persistent pain. This may be explained by the differences in study design. Our criterion for persistent pain was stricter $(\mathrm{NRS} \geqslant 4)$, whereas Poleshuck et al (2006) included all degrees of severity (NRS1-10).

In line with our findings, many previous retrospective studies (Smith et al, 1999; Macdonald et al, 2005; Fecho et al, 2009) and a recent population study (Johansen et al, 2012) have identified positive correlations between persistent postsurgical pain and high BMI. In our study, BMI over 30 was a significant risk factor for persistent pain. Kärki et al (2005) found in their prospective study that higher BMI was associated to neck and shoulder pain at 6 and 12 months after breast cancer surgery. High BMI has been reported to be a risk factor also for persistent pain after joint replacement (Wylde et al, 2011) and other painful conditions (Nilsen et al, 2011; Vandenkerkhof et al, 2011; Wood et al, 2011). High BMI is a proinflammatory condition, which may predispose to chronic pain (Gierman et al, 2012). It is also possible that obesity makes surgery more difficult to perform.

In our study, previous smoking predicted persistent pain more than current smoking. The number of patients who had stopped smoking was high $(24 \%)$. It is possible that the patients had stopped smoking after the diagnosis of breast cancer. Unfortunately, we do not have information about that. There is some evidence that smoking may cause plastic changes in the central nervous system and that these changes remain long after the 
Table I Spearman correlations of all background variables with the outcome variable (pain at 6 month follow-up) and results of the multivariate analysis showing the variables included in the Bayesian model

\begin{tabular}{|c|c|c|c|c|c|c|c|}
\hline \multirow[b]{2}{*}{ Questionnaire data } & \multicolumn{2}{|c|}{ Spearman } & \multirow[b]{2}{*}{$\begin{array}{l}\text { Bayes } \\
\text { value }\end{array}$} & \multirow[b]{2}{*}{ OR } & \multirow[b]{2}{*}{$95 \% \mathrm{Cl}$} & \multirow[b]{2}{*}{$\chi^{2}$} & \multirow[b]{2}{*}{ Interpretation } \\
\hline & $\boldsymbol{r}$ & $P$ & & & & & \\
\hline \multicolumn{8}{|l|}{ Variable } \\
\hline BMI & 0.09 & NS & $\begin{array}{c}\leqslant 25 \\
26-30 \\
\geqslant 31\end{array}$ & $\begin{array}{l}0.58 \\
0.84 \\
3.38\end{array}$ & $\begin{array}{l}0.34-0.98 \\
0.47-1.52 \\
1.83-6.24\end{array}$ & 15.32 & $P<0.001$ \\
\hline Chronic pain & 0.29 & $<0.001$ & $\begin{array}{l}\text { No } \\
\text { Yes }\end{array}$ & $\begin{array}{l}0.34 \\
2.99\end{array}$ & $\begin{array}{l}0.20-0.57 \\
1.76-5.08\end{array}$ & 16.30 & $P<0.0001$ \\
\hline Smoking & 0.12 & $<0.01$ & $\begin{array}{c}\text { No } \\
\text { Yes } \\
\text { Stopped }\end{array}$ & $\begin{array}{l}0.50 \\
0.91 \\
2.41\end{array}$ & $\begin{array}{l}0.30-0.85 \\
0.45-1.87 \\
1.41-4.17\end{array}$ & $|0.5|$ & $P<0.01$ \\
\hline Number of previous operations & 0.17 & $<0.001$ & $\begin{array}{l}\leqslant 3 \\
\geqslant 4\end{array}$ & $\begin{array}{l}0.39 \\
2.91\end{array}$ & $\begin{array}{l}0.23-0.67 \\
1.62-5.25\end{array}$ & 11.45 & $P<0.001$ \\
\hline Pain in the area to be operated & 0.29 & $<0.001$ & $\begin{array}{l}\leqslant 3 \\
\geqslant 4\end{array}$ & $\begin{array}{l}0.35 \\
2.90\end{array}$ & $\begin{array}{l}0.16-0.76 \\
1.32-6.39\end{array}$ & 6.98 & $P<0.01$ \\
\hline Age & 0.03 & NS & $\begin{array}{c}<40 \\
40-69 \\
\geqslant 70\end{array}$ & $\begin{array}{l}0.33 \\
0.81 \\
2.01\end{array}$ & $\begin{array}{l}0.05-2.25 \\
0.36-1.81 \\
0.84-4.78\end{array}$ & 2.20 & NS \\
\hline $\begin{array}{l}\text { Hormone replacement therapy, no/yes } \\
\text { Alcohol use, no/yes } \\
\text { Depression (BDI) sum score } \\
\text { State anxiety (STAl-s) sum score } \\
\text { Trait anxiety (STAI-t) sum score }\end{array}$ & $\begin{array}{l}0.17 \\
0.22 \\
0.17 \\
0.17 \\
0.23\end{array}$ & $\begin{array}{l}<0.001 \\
<0.001 \\
<0.001 \\
<0.001 \\
<0.001\end{array}$ & & & & & \\
\hline $\begin{array}{l}\text { Treatment-related data } \\
\text { Risk group I-2-3 } \\
\text { Type of surgery } 1-2-3-4^{\mathrm{b}} \\
\text { Oxycodone consumption, } \mathrm{mg} \mathrm{kg}^{-1} \text { per } 20 \mathrm{~h} \\
\text { Complications of surgery, no/yes } \\
\text { Adjuvant chemotherapy, no/yes } \\
\text { Adjuvant endocrine therapy, no/yes } \\
\text { Radiotherapy, no/yes } \\
\text { Complications of radiotherapy, no/yes }\end{array}$ & $\begin{array}{l}0.18 \\
0.07 \\
0.13 \\
0.24 \\
0.08 \\
0.15 \\
0.22 \\
0.27\end{array}$ & $\begin{aligned} &< 0.001 \\
& N S \\
&<0.01 \\
&<0.001 \\
& \text { NS } \\
&<0.01 \\
&<0.001 \\
&<0.001\end{aligned}$ & & & & & \\
\hline
\end{tabular}

Abberviations: $\mathrm{BDI}=$ Beck depression inventory; $\mathrm{BMI}=$ body mass index; $\mathrm{Cl}=$ confidence interval; $\mathrm{NS}=$ not significant; $\mathrm{OR}=$ odds ratio. ${ }^{\text {a }} \mathrm{St}$ Gallen's prognostic risk groups of breast cancer: I, low risk; 2, intermediate risk; 3, high risk. ${ }^{\text {b}}$ Type of surgery: I, breast conserving surgery and sentinel node biopsy; 2 , breast conserving surgery and axillary evacuation; 3, mastectomy and sentinel node biopsy; 4, mastectomy and axillary evacuation.

person has given up smoking (Perkins et al, 2001). Previous literature supports the finding that smoking is a risk factor for persistent pain (Leboeuf-Yde, 1999; Shi et al, 2010). It has been suggested that smoking causes dysregulation of the endogenous pain control and that oestradiol concentrations are chronically reduced in female smokers (Girdler et al, 2005). Even though there is good evidence to support the relationship between smoking and chronic pain, the causality is complex. In addition to the effects of nicotine, several other components of cigarette smoke may be involved. Chronic exposure to carbon monoxide increases the level of heme oxygenase and the heme oxygenase-carbon monoxide system regulates, for example, inflammation and oxidative stress (Carraway et al, 2002; Slebos et al, 2003; Mirza et al, 2005). Launay et al (2009) have also suggested that smoking induces epigenetic changes in the $M A O$ gene leading to increased production of the enzyme. This could lead to decreased levels of pain inhibitory monoamines in the central nervous system and increased pain sensitivity. Our results are somewhat contradictory to previous reports and further research is needed to understand the relationship between present and previous smoking and chronic pain. Smoking has many other deleterious health effects and patients should still be encouraged to stop smoking.

Age was one variable in the six-factor model even though the correlation between age and persistent pain was not significant in logistic regression. Age over 70, however, increased the risk of persistent pain nearly eight-fold. Many previous studies have identified younger age as a significant risk factor for persistent postsurgical pain (Poleshuck et al, 2006; Steegers et al, 2008;
Gärtner et al, 2009). In our study, older age was related to more intense pain at the follow-up. Many of the previous studies that have found a connection between age and increased risk for postsurgery pain have not analysed the severity of pain (Andersen and Kehlet, 2011). Gärtner et al (2009) found that young age was a significant risk factor for persistent postoperative pain at the 2-3year follow-up only if all intensities of pain were considered. When only pain that was moderate to severe (NRS $\geqslant 4$ out of 10 ) was considered, age was not a predictive factor. In addition, Poleshuck et al (2006) and Steegers et al (2008) found age to be a significant factor only when they included all intensities of pain (VAS 1-10). The cutoff point for pain in our study was NRS $\geqslant 4$ out of 10 .

We considered moderate to severe pain (NRS $\geqslant 4$ out of 10 ) as a clinically significant cutoff. Tengrup et al (2000) have reported that pain intensities of $<3$ should not significantly affect daily activities. Women who had undergone breast cancer surgery reported only some interference by pain to daily activities when the intensity of pain was estimated to be 1-3 out of 10 (Vilholm et al, 2008). It can also be difficult to make a difference between mild pain and strange sensations in the operated area. It is possible that younger patients experience milder pain as more harmful than older patients due to their different life situation. Younger patients are physically and occupationally more active. It is also possible that older women do not pay as much attention to milder pain as younger women do, based on longer experience of lifetime pain. However, they may become more aware of intense pain when it occurs. There is also some evidence to suggest that the pain perception system changes over the years (Gibson and Helme, 
2001). If the intensity of pain is not taken into account the results may give a false impression that younger patients suffer more postoperative pain than the older.

The intensity of postoperative acute pain, assessed by postoperative opioid (oxycodone) consumption, was related to an increased risk of persistent postoperative pain (Table 1). However, it did not improve the Bayesian model as a predictive factor. In other types of surgery intensity of acute postoperative pain has often been reported to be a risk factor for persistent postoperative pain (Katz et al, 1996; Peters et al, 2007). Some studies that have found this relationship after breast cancer surgery have been retrospective (Tasmuth et al, 1995, 1997) or with a quite small sample size (Hickey et al, 2010). Tasmuth et al (1996b) showed that the patients' report regarding the intensity of previous postoperative pain was influenced by the intensity of current pain.

Psychosocial factors have been reported to influence pain persistence after other types of surgery (Brander et al, 2003; Geiss et al, 2005; Peolsson et al, 2006). In our study, we assessed emotional functioning and distress with self-report questionnaires. Depression, state anxiety and trait anxiety correlated with pain at the 6 months' follow-up but they were not fitted in the predictive Bayesian models. These findings are consistent with the results of Poleshuck et al (2006). The percentage of patients with moderate or severe postoperative pain was small. In addition, our patients reported an average fairly low scores in the preoperative depression and anxiety questionnaires. Symptoms of anxiety and depression are in part overlapping as was seen in our study in the strong intercorrelations between the sum scores. An evaluation of general psychological distress (Keefe et al, 2004), instead of assessing anxiety and depression separately, could give more strength to the statistical analysis of the relationships between psychological distress and pain.

Interestingly, the risk factors identified in this study are those that are known to affect pain persistence in general and not those related to the treatment (surgery, adjuvant treatment) as indicated by the previous mainly retrospective studies that have not assessed factors such as BMI, other chronic pains or smoking. The strength of our study is that it is prospective with a large sample of patients and a reasonably long follow-up. Most of the previous prospective studies have had small sample sizes of about 100 patients (Andersen and Kehlet, 2011). On the basis of our findings, we were able to construct a clinical tool for preoperative identification of patients at risk of developing chronic pain in the operated area. This tool could be used to target preventive interventions to those at the highest risk as 'yellow flags' are used to target risk factors for persistent musculoskeletal pain (Nicholas et al, 2011). Most of the risk factors

\section{REFERENCES}

Andersen KG, Kehlet H (2011) Persistent pain after breast cancer treatment: a critical review of risk factors and strategies for prevention. J Pain 12: 725-746

Beck AT, Ward CH, Mendelson M, Mock J, Erbaugh J (1961) An inventory for measuring depression. Arch Gen Psychiatry 4: 561-571

Bowsher D (1997) The effects of pre-emptive treatment of postherpetic neuralgia with amitriptyline: a randomized, double-blind, placebocontrolled trial. I Pain Symptom Manage 13: 327-331

Brander VA, Stulberg SD, Adams AD, Harden RN, Bruehl S, Stanos SP, Houle T (2003) Predicting total knee replacement pain: a prospective, observational study. Clin Orthop Relat Res 416: 27-36

Breivik H, Cherny N, Collett B, de Conno F, Filbet M, Foubert AJ, Cohen R, Dow L (2009) Cancer-related pain: a pan-European survey of prevalence, treatment, and patient attitudes. Ann Oncol 20: 1420-1433

Cabodi S, Taverna D (2010) Interfering with inflammation: a new strategy to block breast cancer self-renewal and progression? Breast Cancer Res 12: 305

Caffo O, Amichetti M, Ferro A, Lucenti A, Valduga F, Galligioni E (2003) Pain and quality of life after surgery for breast cancer. Breast Cancer Res Treat 80: $39-48$ (e.g., old age, chronic pain conditions, previous smoking and a high number of previous operations) cannot, however, be specifically targeted. One approach to minimise persistent postsurgery pain could be to use preemptive analgesia that reduces pain sensitisation. Amitriptyline (Bowsher, 1997) and gabapentin or pregabalin (Clarke et al, 2012) have been used to this effect. A threshold of 20 on the risk sum score for initiating, for example, amitriptyline would identify $81 \%$ of those who would develop persistent pain. However, the false positive rate would be $56 \%$ resulting in 189 patients receiving the treatment unnecessarily.

It was challenging to find a balance between the sensitivity and specificity of the screening instrument to identify patients at risk to develop persistent pain. A five-factor model was simpler to use but it did not identify enough patients at risk and it included too many false positives. Thus, the six-factor model was chosen. None of the psychological- or the treatment-related variables improved the statistical model. As a next step, we need to assess in more depth how some of these factors, for example extent of axillary surgery, nerve injury, radiotherapy and significant psychological distress will affect the model in a larger patient sample with a longer follow-up.

We chose to use 6 months as the end point in the study even though the original definition for chronic postsurgery pain is 2 months (Macrae, 2001). However, 2 months may not be a relevant timeline regarding pain after breast cancer surgery as adjuvant therapies will continue longer. We will follow the patients of this study for 5.5 years to assess the natural course of pain following breast cancer treatment.

We have created a simple model where the observed variables of one single patient can be used to calculate a risk score for persistent pain after breast cancer surgery. The validity of this tool should now be tested in larger trials. The model can also be further refined when more detailed information and longer follow-ups of larger patient samples are available.

\section{ACKNOWLEDGEMENTS}

Funding was received from the Academy of Finland (grant numbers 110489 and 217028), The Finnish Cancer Organisations, and The Research Funds of the Helsinki and Uusimaa Hospital District (TYH2008225 and TYH2010210). We are indebted to Eija $\mathrm{R}$ Ruoppa, RN and Minna Kaiponen, RN Department of Anaesthesia, Helsinki University Central Hospital, for excellent assistance throughout the project.

Carraway MS, Ghio AJ, Suliman HB, Carter JD, Whorton AR, Piantadosi CA (2002) Carbon monoxide promotes hypoxic pulmonary vascular remodeling. Am J Physiol Lung Cell Mol Physiol 282: L693-L702

Clarke H, Bonin RP, Orser BA, Englesakis M, Wijeysundera DN, Katz J (2012) The prevention of chronic postsurgical pain using gabapentin and pregabalin: A combined systematic review and meta-analysis. Anesth Analg 115: 428-442

Eccleston C, Crombez G (1999) Pain demands attention: a cognitiveaffective model of the interruptive function of pain. Psychol Bull 125: 356-366

Fecho K, Miller NR, Merritt SA, Klauber-Demore N, Hultman CS, Blau WS (2009) Acute and persistent postoperative pain after breast surgery. Pain Med 10: 708-715

Gärtner R, Jensen MB, Nielsen J, Ewertz M, Kroman N, Kehlet H (2009) Prevalence of and factors associated with persistent pain following breast cancer surgery. JAMA 302: 1985-1992

Geiss A, Rohleder N, Kirschbaum C, Steinbach K, Bauer HW, Anton F (2005) Predicting the failure of disc surgery by a hypofunctional HPA axis: evidence from a prospective study on patients undergoing disc surgery. Pain 114: 104-117 
Gerbershagen HJ, Ozgur E, Dagtekin O, Straub K, Hahn M, Heidenreich A, Sabatowski R, Petzke F (2009) Preoperative pain as a risk factor for chronic post-surgical pain - six month follow-up after radical prostatectomy. Eur J Pain 13: 1054-1061

Gerbershagen HJ, Rothaug J, Kalkman CJ, Meissner W (2011) Determination of moderate-to-severe postoperative pain on the numeric rating scale: a cut-off point analysis applying four different methods. $\mathrm{Br} J$ Anaesth 107: 691-626

Gibson SJ, Helme RD (2001) Age-related differences in pain perception and report. Clin Geriatr Med 17: 433-456

Gierman LM, van der Ham F, Koudijs A, Wielinga PY, Kleemann R, Kooistra T, Stoop R, Kloppenburg M, van Osch GJ, Stojanovic-Susulic V, Huizinga TW, Zuurmond AM (2012) Metabolic stress-induced inflammation plays a major role in the development of osteoarthritis in mice. Arthritis Rheum 64: 1172-1181

Girdler SS, Maixner W, Naftel HA, Stewart PW, Moretz RL, Light KC (2005) Cigarette smoking, stress-induced analgesia and pain perception in men and women. Pain 114: 372-385

Goldhirsch A, Glick JH, Gelber RD, Coates AS, Thürlimann B, Senn H-J, 9th St Gallen conference (2005) Meeting Highlights: International Expert Consensus on the primary therapy of early breast cancer 2005. Ann Oncol 16: 1569-1583

Goldhirsch A, Wood WC, Gelber RD, Coates AS, Thurlimann B, Senn HJ, 10th St. Gallen conference (2007) Progress and promise: highlights of the international expert consensus on the primary therapy of early breast cancer 2007. Ann Oncol 18: 1133-1144

Hickey OT, Burke SM, Hafeez P, Mudrakouski AL, Hayes ID, Shorten GD (2010) Severity of acute pain after breast surgery is associated with the likelihood of subsequently developing persistent pain. Clin J Pain 26: 556-560

Hinrichs-Rocker A, Schulz K, Jarvinen I, Lefering R, Simanski C, Neugebauer EA (2009) Psychosocial predictors and correlates for chronic post-surgical pain (CPSP) - a systematic review. Eur J Pain 13: 719-730

Johansen A, Romundstad L, Nielsen CS, Schirmer H, Stubhaug A (2012) Persistent postsurgical pain in a general population: prevalence and predictors in the Tromso study. Pain 153: 1390-1396

Jung BF, Herrmann D, Griggs J, Oaklander AL, Dworkin RH (2005) Neuropathic pain associated with non-surgical treatment of breast cancer. Pain 118: 10-14

Kainu JP, Sarvela J, Tiippana E, Halmesmaki E, Korttila KT (2010) Persistent pain after caesarean section and vaginal birth: a cohort study. Int J Obstet Anesth 19: 4-9

Karki A, Simonen R, Malkia E, Selfe J (2005) Impairments, activity limitations and participation restrictions 6 and 12 months after breast cancer operation. J Rehabil Med 37: 180-188

Katz J, Jackson M, Kavanagh BP, Sandler AN (1996) Acute pain after thoracic surgery predicts long-term post-thoracotomy pain. Clin J Pain 12: 50-55

Keefe FJ, Rumble ME, Scipio CD, Giordano LA, Perri LM (2004) Psychological aspects of persistent pain: current state of the science. $J$ Pain 5: 195-211

Kehlet H, Jensen TS, Woolf CJ (2006) Persistent postsurgical pain: risk factors and prevention. Lancet 367: 1618-1625

Kudel I, Edwards RR, Kozachik S, Block BM, Agarwal S, Heinberg LJ, Haythornthwaite J, Raja SN (2007) Predictors and consequences of multiple persistent postmastectomy pains. J Pain Symptom Manage 34: 619-627

Kurki TS, Kataja M (1996) Preoperative prediction of postoperative morbidity in coronary artery bypass grafting. Ann Thorac Surg 61: 1740-1745

Launay JM, Del Pino M, Chironi G, Callebert J, Peoc'h K, Megnien JL, Mallet J, Simon A, Rendu F (2009) Smoking induces long-lasting effects through a monoamine-oxidase epigenetic regulation. PLoS One 4: e7959

Leboeuf-Yde C (1999) Smoking and low back pain. A systematic literature review of 41 journal articles reporting 47 epidemiologic studies. Spine 24: 1463-1470

Lobner M, Luppa M, Matschinger H, Konnopka A, Meisel HJ, Gunther L, Meixensberger J, Angermeyer MC, Konig HH, Riedel-Heller SG (2012) The course of depression and anxiety in patients undergoing disc surgery: a longitudinal observational study. J Psychosom Res 72: 185-194

Macdonald L, Bruce J, Scott NW, Smith WC, Chambers WA (2005) Longterm follow-up of breast cancer survivors with post-mastectomy pain syndrome. $\mathrm{Br} J$ Cancer 92: 225-230

Macrae WA (2001) Chronic pain after surgery. Br J Anaesth 87: 88-98

Mirza A, Eder V, Rochefort GY, Hyvelin JM, Machet MC, Fauchier L, Bonnet P (2005) CO inhalation at dose corresponding to tobacco smoke worsens cardiac remodeling after experimental myocardial infarction in rats. Toxicol Sci 85: 976-982

Nicholas MK, Linton SJ, Watson PJ, Main CJ, 'Decade of the Flags' Working Group (2011) Early identification and management of psychological risk factors ('yellow flags') in patients with low back pain: a reappraisal. Phys Ther 91: 737-753

Nilsen TI, Holtermann A, Mork PJ (2011) Physical exercise, body mass index, and risk of chronic pain in the low back and neck/shoulders: longitudinal data from the Nord-Trondelag Health Study. Am Epidemiol 174: 267-273

Pelkonen T, Roine I, Monteiro L, Cruzeiro ML, Pitkaranta A, Kataja M, Peltola H (2012) Prognostic accuracy of five simple scales in childhood bacterial meningitis. Scand J Infect Dis 44: 557-565

Peolsson A, Vavruch L, Oberg B (2006) Predictive factors for arm pain, neck pain, neck specific disability and health after anterior cervical decompression and fusion. Acta Neurochir 148: 167-173; discussion 173

Perkins KA, Gerlach D, Broge M, Sanders M, Grobe J, Fonte C, Cherry C, Wilson A, Jacob R (2001) Quitting cigarette smoking produces minimal loss of chronic tolerance to nicotine. Psychopharmacology 158: 7-17

Peters ML, Sommer M, de Rijke JM, Kessels F, Heineman E, Patijn J, Marcus MA, Vlaeyen JW, van Kleef M (2007) Somatic and psychologic predictors of long-term unfavorable outcome after surgical intervention. Ann Surg 245: 487-494

Poleshuck EL, Katz J, Andrus CH, Hogan LA, Jung BF, Kulick DI, Dworkin RH (2006) Risk factors for chronic pain following breast cancer surgery: a prospective study. J Pain 7: 626-634

Shi Y, Weingarten TN, Mantilla CB, Hooten WM, Warner DO (2010) Smoking and pain: pathophysiology and clinical implications. Anesthesiology 113: 977-992

Slebos DJ, Ryter SW, Choi AM (2003) Heme oxygenase-1 and carbon monoxide in pulmonary medicine. Respir Res 4: 7

Smith WC, Bourne D, Squair J, Phillips DO, Chambers WA (1999) A retrospective cohort study of post mastectomy pain syndrome. Pain 83: 91-95

Spielberger CD, Gorsuch RL, Lushene PR, Vagg PR, Jacobs AG (1983) Manual for the State-Trait Anxiety Inventory (Form Y). Consulting Psychologists Press, Inc: Palo Alto

Steegers MA, Wolters B, Evers AW, Strobbe L, Wilder-Smith OH (2008) Effect of axillary lymph node dissection on prevalence and intensity of chronic and phantom pain after breast cancer surgery. J Pain 9: 813-822

Stevens PE, Dibble SL, Miaskowski C (1995) Prevalence, characteristics, and impact of postmastectomy pain syndrome: an investigation of women's experiences. Pain 61: 61-68

Tasmuth T, Estlanderb AM, Kalso E (1996b) Effect of present pain and mood on the memory of past postoperative pain in women treated surgically for breast cancer. Pain 68: 343-347

Tasmuth T, Kataja M, Blomqvist C, von Smitten K, Kalso E (1997) Treatment-related factors predisposing to chronic pain in patients with breast cancer - a multivariate approach. Acta Oncol 36: 625-630

Tasmuth T, von Smitten K, Hietanen P, Kataja M, Kalso E (1995) Pain and other symptoms after different treatment modalities of breast cancer. Ann Oncol 6: 453-459

Tasmuth T, von Smitten K, Kalso E (1996a) Pain and other symptoms during the first year after radical and conservative surgery for breast cancer. Br J Cancer 74: 2024-2031

Tengrup I, Tennvall-Nittby L, Christiansson I, Laurin M (2000) Arm morbidity after breast-conserving therapy for breast cancer. Acta Oncol 39: 393-397

Vandenkerkhof EG, Macdonald HM, Jones GT, Power C, Macfarlane G] (2011) Diet, lifestyle and chronic widespread pain: results from the 1958 British Birth Cohort Study. Pain Res Manag 16: 87-92

Vilholm OJ, Cold S, Rasmussen L, Sindrup SH (2008) The postmastectomy pain syndrome: an epidemiological study on the prevalence of chronic pain after surgery for breast cancer. Br J Cancer 99: 604-610

Vlaeyen JW, Linton SJ (2000) Fear-avoidance and its consequences in chronic musculoskeletal pain: a state of the art. Pain 85: 317-332

Wood D, Goodnight S, Haig AJ, Nasari T (2011) Body mass index, but not blood pressure is related to the level of pain in persons with chronic pain. J Back Musculoskelet Rehabil 24: 111-115

Wylde V, Hewlett S, Learmonth ID, Dieppe P (2011) Persistent pain after joint replacement: Prevalence, sensory qualities, and postoperative determinants. Pain 152: 566-572

This work is published under the standard license to publish agreement. After 12 months the work will become freely available and the license terms will switch to a Creative Commons Attribution-NonCommercial-Share Alike 3.0 Unported License. 


\section{APPENDIX}

Table Al Weighted values for the six variables in the Bayesian risk model

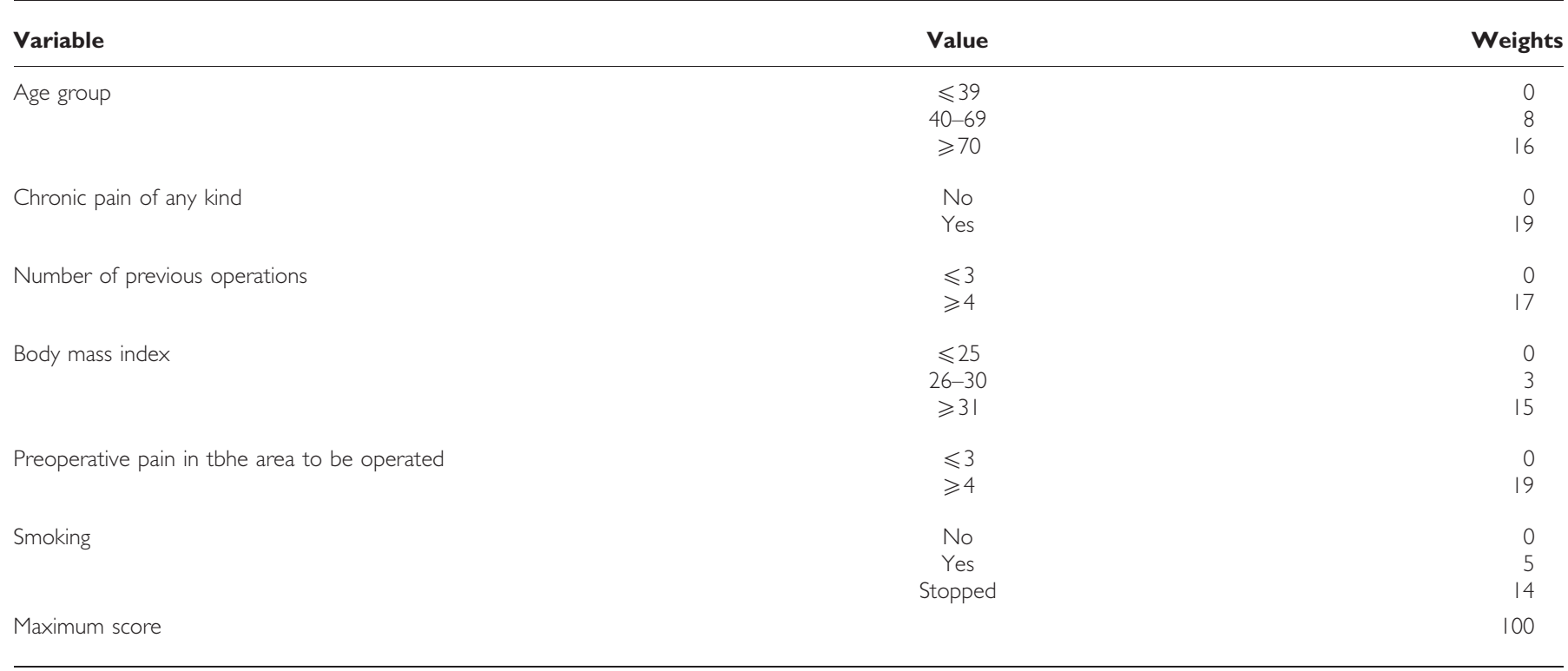

Table A2 Sensitivity and specificity of the six-factor model at different cutoff levels

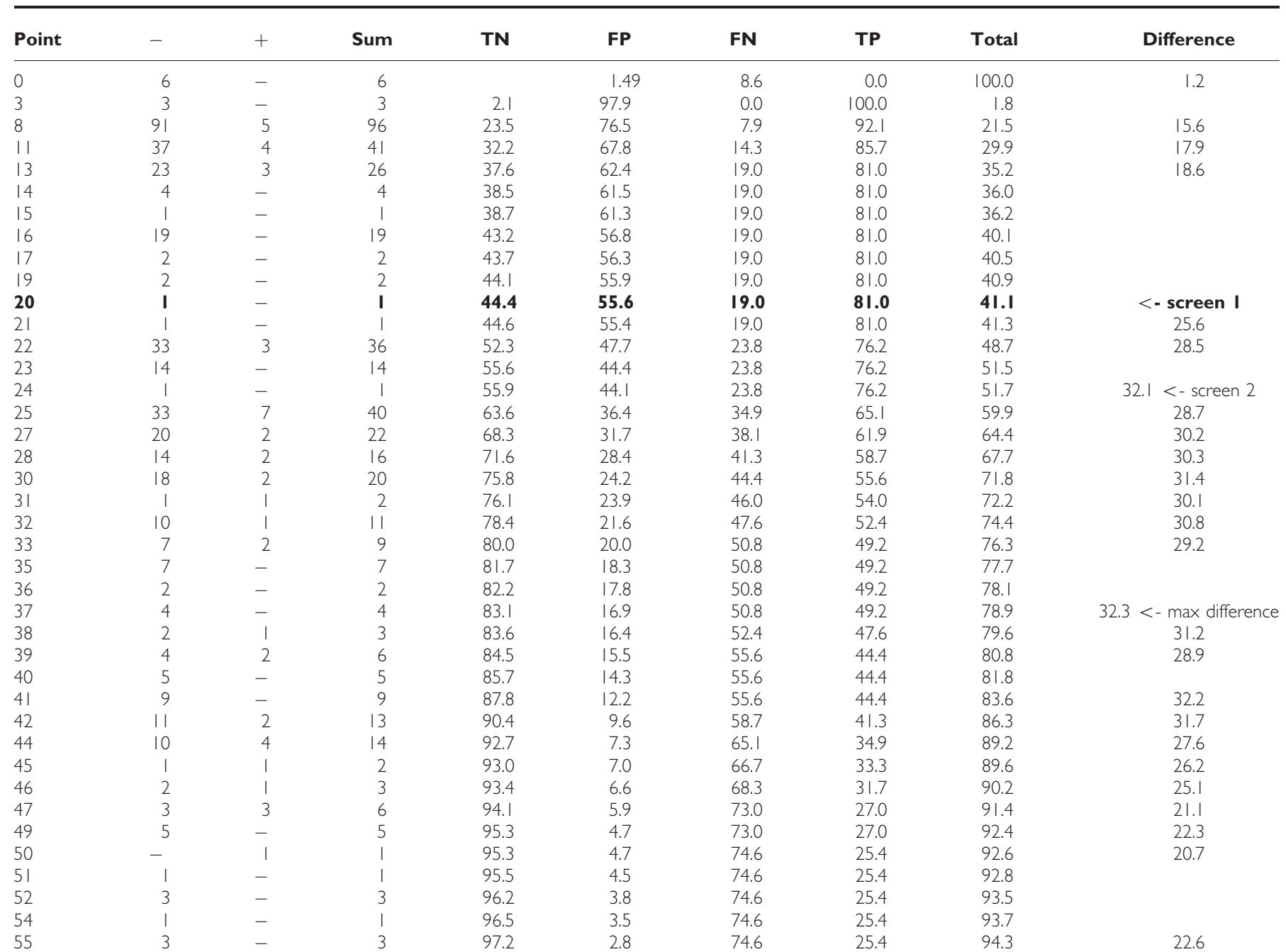


Risk factors for persistent pain after breast cancer surgery R Sipilä et al

1466

Table A2 (Continued)

\begin{tabular}{|c|c|c|c|c|c|c|c|c|c|}
\hline Point & - & + & Sum & $\mathbf{T N}$ & $\mathbf{F P}$ & $\mathbf{F N}$ & $\mathbf{T P}$ & Total & Difference \\
\hline 56 & 2 & 2 & 4 & 97.7 & 2.3 & 77.8 & 22.2 & 95.1 & 19.9 \\
\hline 58 & 2 & 2 & 4 & 98.1 & 1.9 & 81.0 & 19.0 & 95.9 & \\
\hline 59 & 3 & 1 & 4 & 98.8 & 1.2 & 82.5 & 17.5 & 96.7 & \\
\hline 61 & 3 & 2 & 5 & 99.5 & 0.5 & 85.7 & 14.3 & 97.8 & \\
\hline 64 & - & 2 & 2 & 99.5 & 0.5 & 88.9 & $|1|$. & 98.2 & \\
\hline 66 & 1 & 1 & 2 & 99.8 & 0.2 & 90.5 & 9.5 & 98.6 & \\
\hline 73 & - & 3 & 3 & 99.8 & 0.2 & 95.2 & 4.8 & 99.2 & \\
\hline 74 & - & 1 & 1 & 99.8 & 0.2 & 96.8 & 3.2 & 99.4 & \\
\hline 77 & - & 1 & I & 99.8 & 0.2 & 98.4 & 1.6 & 99.6 & \\
\hline 80 & I & - & 1 & 100.0 & 0.0 & 98.4 & 1.6 & 99.8 & \\
\hline 92 & - & 1 & I & 100.0 & 0.0 & 100.0 & 0.0 & 100.0 & \\
\hline Total & 426 & 63 & 489 & $\mathrm{FP}$ & $\mathrm{TN}$ & TP & $\mathrm{FN}$ & & \\
\hline
\end{tabular}

Abbreviations: $\mathrm{FN}=$ false negative; $\mathrm{FP}=$ false positive; $\mathrm{TN}=$ true negative; $\mathrm{TP}=$ true positive. Wilcoxon $5.556 ; P<0.000000$ I. 